\title{
Distribution Pattern of Frequently Met Phytonematode Genera on Allium sativum (Garlic) in Jammu and Kashmir and a Description Note on Hirschmanniella microtyla Sher, 1968
}

\author{
Sheikh Javaid Hassan \\ Department of Zoology, Government Degree College, Kulgam, Jammu and Kashmir, India
}

Received: $20^{\text {th }}$ November, 2020

Accepted: 27th December, 2020

Published online: $31^{\text {st }}$ December, 2020

https://doi.org/10.33745/ijzi.2020.v06i02.016

\begin{abstract}
Hirschmanniella microtyla Sher, 1968 was predominantly found to occur on Allium sativum. The species was identified on the basis of morphometeric dimensions but the population was found to vary from the original in the value of $\mathrm{V}$ i.e. 57 per cent in the present specimens as compared to 53 per cent in the original dimensions and description by Sher (1968), probably as a result of nematode adaptation to host varaibility. H. microtyla is being reported for the first time in the valley of Kashmir, hence forming new host, new place record of same. The species is earlier reported by Sher (1968) on Vallisneria americana. The study includes the genera build up viz-a-viz their district wise distribution pattern on this host. Hirschmaniella, Psilenchus, Tylenchus, Aglenchus, and Pratylenchus were encountered on examining the soil and root samples of Allium sativum during the period of study. The values reflect that the population build up on the said host is in the decreasing order of Anantnag >Kupwara > Srinagar.
\end{abstract}

Keywords: Allium sativum, Hirschmanniella microtyla, Distribution pattern, Kashmir.

Citation: Sheikh Javaid Hassan: Distribution pattern of frequently met phytonematode genera on Allium sativum (Garlic) in Jammu and Kashmir and a description note on Hirschmanniella microtyla Sher, 1968. Intern. J. Zool. Invest. 6 (2): 360-365, 2020. https://doi.org/10.33745/ijzi.2020.v06i02.016

\section{Introduction}

Nematodes, the most abundant and diverse group, are one of the important components of the soil fauna across all ecosystems. Nematode biodiversity is correlated to the soil health properties owing to their roles in ecosystem services (Neher et al., 2005). Most of the nematode biodiversity studies can be linked to the ecology indicators and sustainable management of the agriculture
(Shi et al., 2008). Yeates (1999) reported that nematode diversity is greatest in ecosystems with least disturbance, and bacterial-feeding nematodes make the greatest contribution to the decomposer food web in more intensively managed ecosystems.

The tylenchida (Throne, 1949) are the largest and economically the most important group of plant parasitic nematodes. The plant 
parasitic Tylenchida, also known as eelworms, phytonematodes, phytohelminthes or simply plant nematodes, are equipped with a protrusible hollow stylet which is thrust into plant tissues for obtaining nutrition after the dissolution of the cell contents. These small worms exploited all plant organs including flowers and seeds, but mostly they attack roots and utilize chemical activity of bacteria, which hydrolyze carbohydrates, split proteins, cellulose and other organic substances of plant origin. These phytophagus nematodes are common pests of vegetable crops and its yield loss is often due to their high densities. Few studies regarding plant parasitic nematodes in India are performed by Prasad (1960) in I.A.R.I. farm on vegetable and fruit crops; Siddiqui (1963) on nematodes of citrus plants in 13 districts of Uttar Pradesh, Prasad et al. (1965) on the nematodes of onion; Khan and Basir (1965) on Scutellonema mangiferae from the soil around the roots of Mangifera indica from U.P.

In the present study an intensive survey of plant parasitic nematodes affecting Allium sativum was conducted in the Kashmir valley.

\section{Materials and Methods}

A total of 60 samples, each of soil and root samples of Allium sativum (Garlic) were collected from three districts (Anantnag, Kupwara, Srinagar) of Jammu and Kashmir, India to work out the distribution pattern of the frequently met nematode genera. Composite root and soil samples were drawn from host at $0-15 \mathrm{~cm}$ depths. A composite root sample of $1 \mathrm{~g}$ from the plants were taken and observed for nematode population. Similarly, a composite soil sample of $200 \mathrm{~g}$ was processed for nematode assay by decanting and sieving followed by the modified Baermann funnel technique. The root samples were more thoroughly washed in running tap water, chopped and thoroughly mixed and the nematode population in root was estimated by traction through maceration by using a kitchen blender. Nematodes collected from soil samples were killed in hot water and later fixed in $4 \%$ formaldehyde solution. Nematode population was estimated by using a stereoscope microscope. Plant parasitic nematodes were identified up to genus level by using standard monograph.

The population sizes of the met genera were correlated to include absolute frequency, absolute density and prominence value to work out the distribution study. The said parameters were calculated as follow:

Frequency $(\mathrm{N})=$ It shows how often a taxon occurs in the collected samples. The frequency of a nematode genus represents the number of samples in which it is found.

Absolute frequency $(\mathrm{AF})=$ Number of samples containing a genus $\div$ Total Number of samples collected $\times 100$

Relative frequency $(\mathrm{RF})=$ Absolute Frequency of a genus $\div$ Sum of Absolute frequencies of all genera $\times 100$

Density (D) $=$ Number of nematodes of the genus in all samples $\div$ Total number of samples collected.

Relative density (RD) $\%=$ Density of the genus $\div$ Sum of densities of all nematode genera $\times 100$

Absolute Density $\%=$ Density of the genus $\div$ Volume or mass units of the sample $\times 100$

Prominence value $(P V)=$ Density $\sqrt{\text { absolute frequency }}$

Relative Prominance Value (RPV) \% = Prominance value of the genus $\div$ Sum of Prominance value of all nematode genera $\times 100$

Mean Intensity $=$ Number of individuals of a genus collected $\div$ Number of infected hosts with that genus.

\section{Results and Discussion}

Hirschmaniella, Psilenchus, Tylenchus, Aglenchus, and Pratylenchus were encountered on examining the soil and root samples of Allium sativum during the period of study. In order to work out the region wise distribution pattern of these commonly met 
genera, the average values of the prevalence parameters were statistically calculated. Aglenchus was met with the highest percentage of Absolute frequency of $97 \%$ in District Anantnag. Srinagar has the lowest absolute frequency of $64 \%$ in case of Hirschmaniella. $27.4 \%$ of relative frequency was met in Anantnag in the population of Aglenchus. Absolute density of 37.9\% was calculated for Tylenchus in the District Anantnag and the corresponding lowest value was met in District Srinagar. Psilenchus has highest proportion of absolute density of $37.9 \%$ and lowest value of $22 \%$ in case of Pratylenchus. The mean intensity value of the said genera are 93, 96, 75, 60 and 54, respectively (Table 1, Fig.1). The values reflect that the population build up on the said host is in the decreasing order of Anantnag $>$ Kupwara $>$ Srinagar (Fig. 2). The reasons can be attributed to the soil texture, soil moisture and climatic conditions over a period of the year.

The present results in regard with the survey and population analysis part on this host is in good conformity with the work of other researchers over different parts of the world. A general survey of plant parasitic nematodes associated with Sweet potato in Niger was carried out by (Haougui et al., 2011) whose results validate the present variables. Bhattacharya et al. (2012) studied the biodiversity of plant parasitic nematodes of Cashew Plantations in Tripura, India and listed the similar results. Plant parasitic nematodes associated with vegetables growing greenhouses in south eastern Anatolia region, Turkey were studied by Tan and Kilic (2012) depicting sort of similar results. Studies of other investigators (Fotedar and Mahajan, 1972; Fotedar and Handoo, 1977; Javaidhassan et al., 2009; Kaul, 1985; Manjrekar and Talgeri, 1969; Mahajan 1973) conform well with the present results.

Hirschmanniella microtyla Sher, 1968 was predominantly found to occur on Allium sativum. The species was identified on the basis of morphometeric dimensions which did vary from the original dimensions and description as by Sher (1968) probably as a result of nematode adaptation to host variability. The description note is detailed hereunder.

\section{Hirschmanniella microtyla Sher, 1968}

Female: $\quad L=0.94-1.37, a=37.5-53.3, b=$ $8.1-10.0 \mathrm{c}=13-18, c^{\prime}=3.4-4.4, \mathrm{v}=57-$ $59 \%$, stylet $=17.9-21 \mu$

Male: $\quad \mathrm{L}=0.96-1.145, \mathrm{a}=37-47, \mathrm{~b}=8.6$ $-10.6, c=15.3-17.1, c^{\prime}=3.4-4.1$, Stylet $=$ $20.3-21.0 \mu$.

( $\mathrm{L}=$ total body length in mm; $\mathrm{a}=$ body length divided by greatest body width; $\mathrm{b}=$ body length divided by distance from anterior end to junction of oesophagus and intestine; $\mathrm{c}=$ body length divided by tail length; $\mathrm{c}^{\prime}$ = tail length divided by body width at anus or cloaca; $\mathrm{V}=$ distance of vulva from anterior end X100 $\div$ body length).

Lip region hemispherical, 6 annules, Stylet knobs large, rounded, excretory pore slightly anterior to oesophago-intestinal valve. Intestine not overlaping rectum. Outer bands of lateral fields incompletely aereolated in posterior part of body. Body annules near tail terminus absent. Tail terminus with pointed peg like extension. Males appear to be rare in this species.

Habitat and Locality: The specimens were collected in the soil around roots of Allium sativum (garlic) from Kashmir valley. 
Table 1: Community analysis of plant parasitic nematodes associated with Allium sativum (Garlic) and its district wise distribution pattern

\begin{tabular}{|c|c|c|c|c|c|c|c|}
\hline Genus & District & AF (\%) & RF (\%) & RD (\%) & AD (\%) & RPV (\%) & MI \\
\hline \multirow[t]{3}{*}{ Hirschmaniella, } & Kupwara & 70 & 16.5 & 20.8 & 33 & 19 & 93 \\
\hline & Srinagar & 64 & 14 & 17.6 & 27.7 & 17.3 & 88 \\
\hline & Anantnag & 74 & 21 & 23.7 & 36 & 23 & 96 \\
\hline \multirow[t]{3}{*}{ Psilenchus } & Kupwara & 73.3 & 17.3 & 22.7 & 36 & 21 & 96 \\
\hline & Srinagar & 67 & 17 & 21.1 & 31.9 & 21 & 92 \\
\hline & Anantnag & 77 & 21 & 27.9 & 42 & 26.7 & 99 \\
\hline \multirow[t]{3}{*}{ Tylenchus } & Kupwara & 90 & 21 & 21.7 & 34.5 & 22.6 & 75 \\
\hline & Srinagar & 87 & 17 & 19 & 31 & 21 & 72 \\
\hline & Anantnag & 93 & 23.7 & 23 & 37.9 & 26.6 & 78 \\
\hline \multirow[t]{3}{*}{ Aglenchus } & Kupwara & 96.6 & 23 & 18.5 & 29.4 & 20 & 60 \\
\hline & Srinagar & 90 & 20.7 & 17 & 27 & 18 & 56 \\
\hline & Anantnag & 97 & 27.4 & 22 & 30.6 & 28 & 72 \\
\hline \multirow[t]{3}{*}{ Pratylenchus } & Kupwara & 93.3 & 22 & 16 & 25.5 & 17 & 54 \\
\hline & Srinagar & 89 & 14 & 17 & 22 & 22 & 56 \\
\hline & Anantnag & 96.3 & 26.4 & 21 & 27 & 21 & 63 \\
\hline
\end{tabular}

$\mathrm{AF}=$ Absolute frequency, $\mathrm{RF}=$ Relative frequency, $\mathrm{RD}=$ Relative Density, $\mathrm{AD}=$ Absolute density, $\mathrm{RPV}=$ Relative prominence value, MI= Mean Intensity.

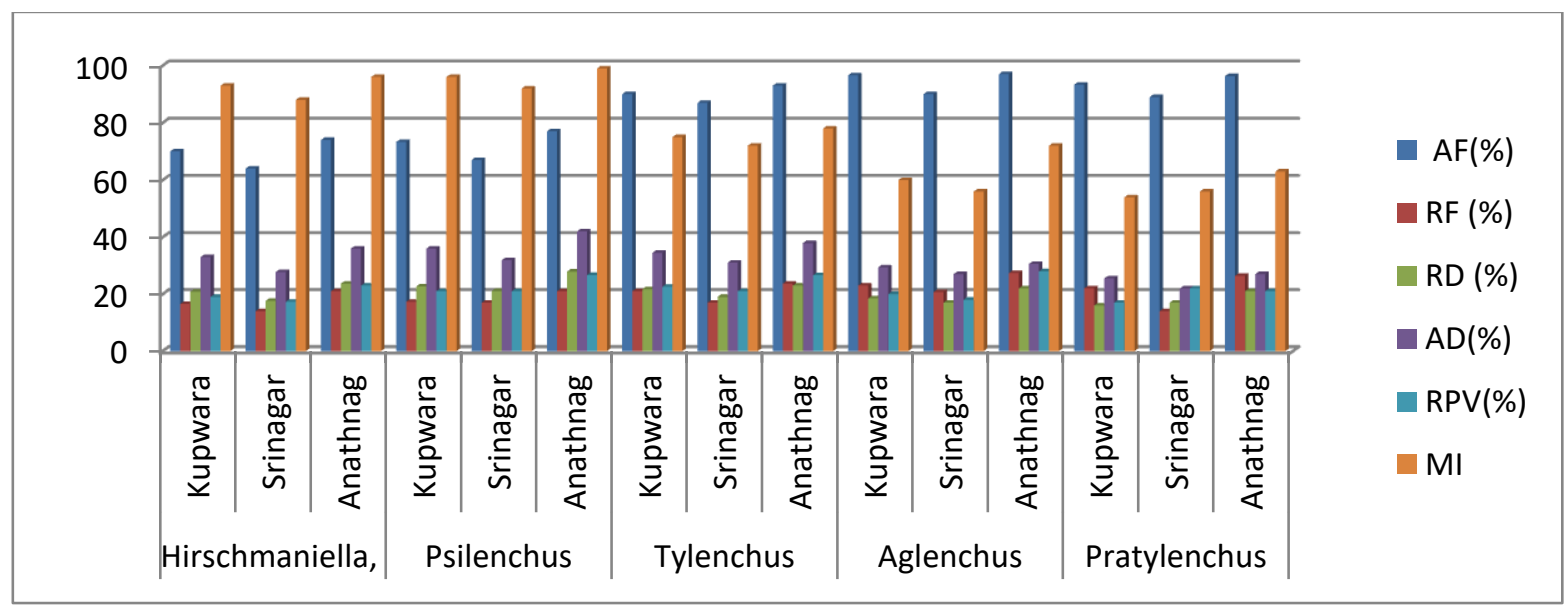

Fig.1: Graphical representation of genera build up vis-a-vis their district wise distribution pattern. 


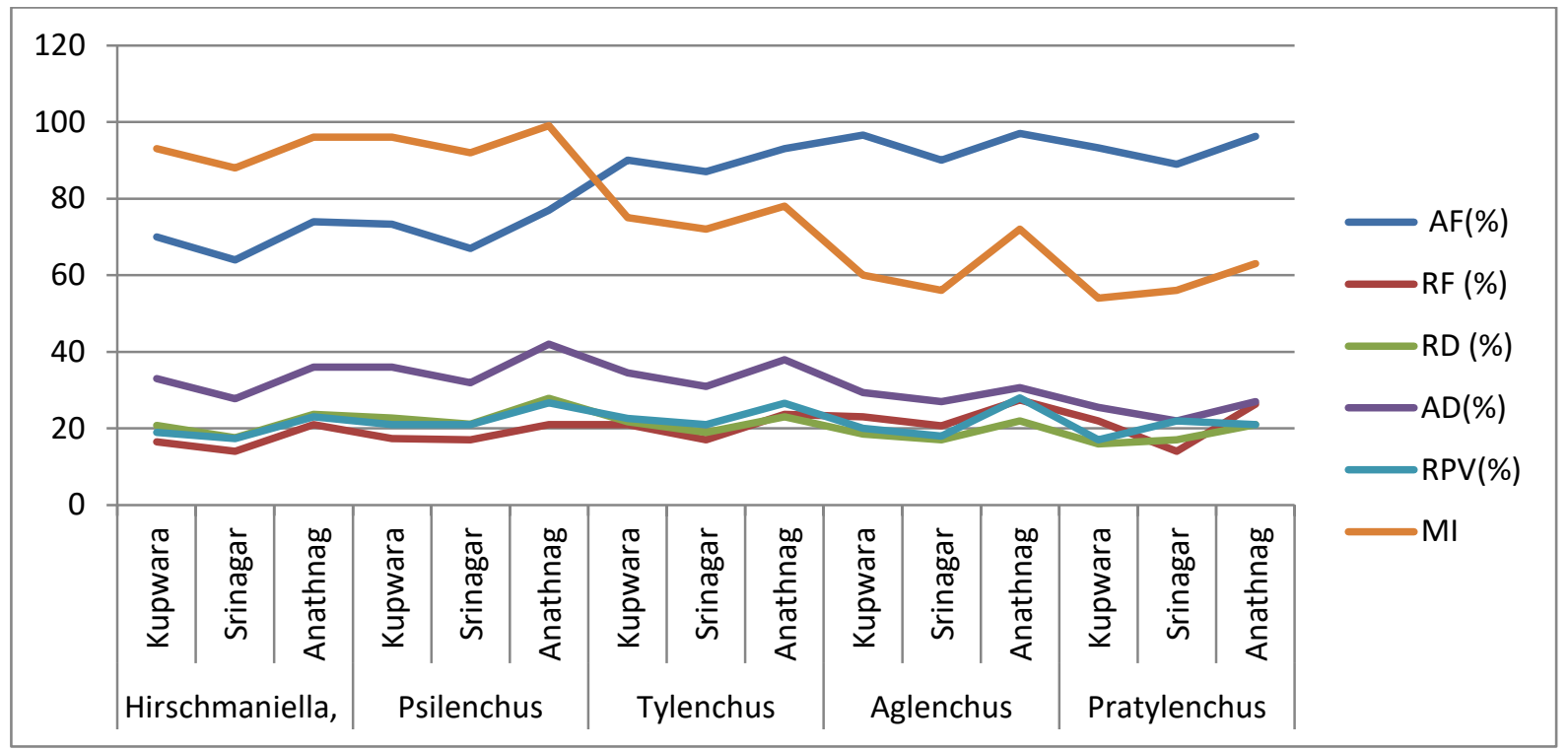

Fig. 2: Graphical representation of various parameters of genera build up vis-a-vis their district wise distribution pattern.
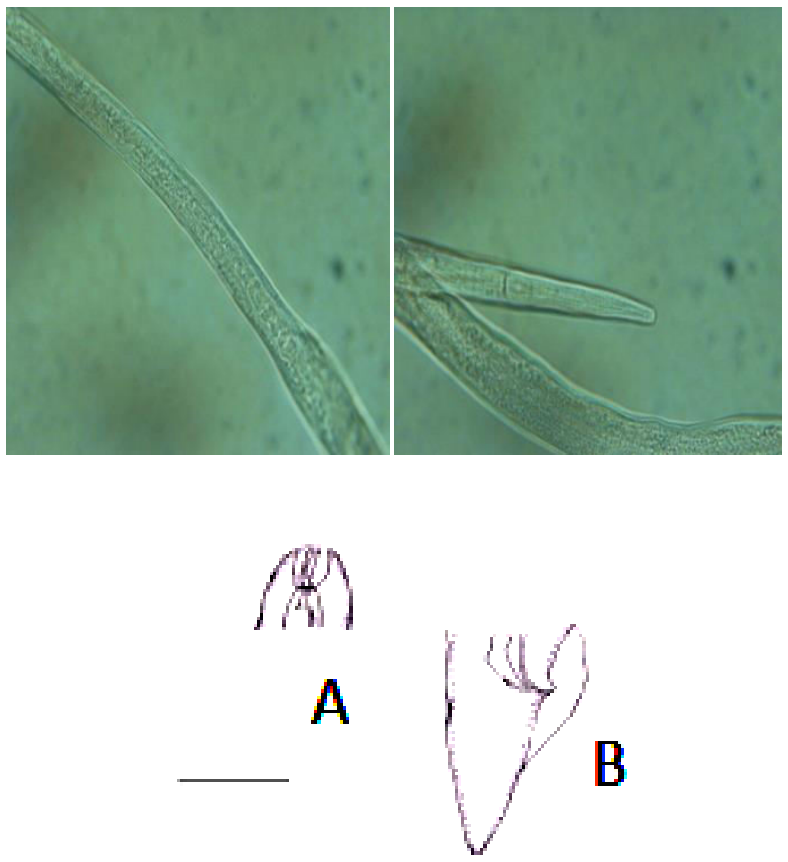

Hirschmaniella microtyla Sher, 1968

A---- Anterior end of female.

B---- Male posterior region. Measuring scale $=100 \mathrm{x}$

Remarks: The H. microtyla is being reported for the first time in the valley of Kashmir, hence forming new host, new place record of same. The species is earlier reported by Sher (1968) on Vallisneria americana. The variation is in the value of $\mathrm{V}$ i.e. 57 per cent in the present specimens as compared to 53 per cent in the original dimensions and description as by Sher (1968).

\section{References}

Bhattacharya C, Dasgupta MK and Mukherjee B. (2012) Biodiversity of plant parasitic nematodes of cashew plantations in Tripura. India. Nematol. Medit. 40:163-168.

Cobb NA. (1918) Estimating the nema population of soil. Agric. Tech. Circ. U.S. Deptt. Agric. 1: 48.

Fotedar DN and Handoo ZA. (1977) Aertylenchus safroni N. gen., n. sp. (nematodes : Tylenchida) from Kashmir. Indian J. Nematol. 7: 145-147.

Fotedar DN and Mahajan R. (1972) A new species of the genus Basiria Siddiqi, 1954 from around the roots of Brassica oleracea in Kashmir. Proc. Ind. Sci. Cong, III, 453.

Fotedar DN and Mahajan R. (1974) Four new species of the genus Helicotylenchus Steiner, 1945 (Nematoda: Hoplolaminae) from India. Rivista Parasitol. 35: 119-124.

Haougui A, Doumma A and Toufique BM. (2011) Survey of plant parasitic nematodes associated with sweet potato in Niger. Asian J. Agr. Sci. 3:32-36.

Hassan J. (2009) Nematodes associated with Zea mays and their control through organic soil amendments. Intern. J. Plant Prod. 3: 73- 78. 
Kaul V. (1985) Studies on the plant parasitic nematodes of Kashmir. Ph. D. thesis submitted to Department of Zoology, University of Kashmir, Srinagar.

Khan SH and Basir MA. (1965) Scutellonema magnifera n. sp. (Nematoda : Hoplolaimidae) from India. Proc. Helminth Soc. Wash. 32: 136 -138.

Mahajan R. (1973) Two new nematodes Tylenchus kashmiriensis n. sp. (Tylenchidae) and Dorylaimoides pari n. sp. (Dorylaimoididae) from Kashmir, India. Rivista Parasitol. 34: 201-204.

Manjrekar MD and Talgeri GM. (1969) Problems of plant parasitic nematodes in Maharashtra (abstr). All India Nematology Symposium IARI, New Delhi.

Neher DA, Wu J, Barbercheck ME and Anas 0. (2005) Ecosystem type affects interpretation of soil nematode community measures. Appl. Soil Ecol. 30: 47-64.

Prarad SK. (1960) Plant parasitic nematodes observed at I.A.R.I farm. Indian J. Ent. 22 : 127-128.

Prasad SK, Khan E and Chawla ML. (1965) Two new species of Helicotylenchus from soil around maize roots in India. Indian J. Ent. 27: 182-184.

Sher SA. (1968) Revision of the genus Hirschmaniella Luc and Goodey, 1963 (Nematoda : Tylenchoidea). Nematol.14 : 243-275.
Shi CJ, Zhang XK, Jiang Y, Jiang DM and Steinberger Y. (2008) Geostatistical analysis of soil nematodes communities under degraded and meliorated grasslands in the Horqin sand land. Amer- Eurasian J. Agric. Environ. Sci. 4: 55-61.

Siddiqi MR. (1963) Distribution of the nematode parasites of citrus in Uttar Pradesh. J. Sci. Tech. 1: 51-52.

Siddiqi MR. (1970) On the plant parasitic nematodes genera Merlinius gen. $n$. and Tylenchorhynchus Cobb and the classification of the families Dolichodoridae and Belonolaimidae n. rank. Proc. Helminth. Soc. Wash. 37: 68-77.

Tan AN and Kilic M. (2012) Plant parasitic nematodes associated with vegetable growing greenhouses in south eastern anatolia region. Turkey. African J. Agr. Res. 7):2777-2790.

Throne G. (1949) On the classification Tylenchida, new order (Nematoda: Phasmida). Proc. Helm. Soc. Wash. 16: 37-73.

Yeates GW. (1999) Effects of plants on nematode community structure. Ann. Rev. Phytopathol. 37: 127-149. 